\title{
The comparison of burnout on the three directions of $Y$ test in the basketball players with ankle instability
}

\author{
Hamid Khorramnezhad $^{2}$, Hamid Dehnavi ${ }^{1}$, Mahdi Seyed Alhosseini ${ }^{3}$, Hamid Hassanpanah ${ }^{1}$ \\ ${ }^{1}$ Sama Technical and Vocational Training College, Islamic Azad University, Neyshabur Branch, Neyshabur, IRAN \\ ${ }^{2}$ Department of Sport Injury and Corrective Exercises, School of Physical Education and Sport Sciences, Shahid Bahonar University of \\ Kerman, Kerman, Iran \\ ${ }^{3}$ M.S of Physical Education and Sport Science, Farhangian University, Daneshvar Branch, Neyshabur, Iran
}

\section{Email address:}

h_khorramnezhad@yahoo.com(H. Khorramnezhad)

\section{To cite this article:}

Hamid Khorramnezhad, Hamid Dehnavi, Mahdi Seyed Alhosseini, Hamid Hassanpanah. The Comparison of Burnout on the Three Directions of Y Test in the Basketball Players with Ankle Instability. American Journal of Sports Science. Vol. 1, No. 3, 2013 , pp. 33-38. doi: 10.11648/j.ajss.20130103.12

\begin{abstract}
Maintaining dynamic balance in daily activities and desirable sport functions is indeed crucial. The purpose of the present study was to compare the burnout on the three directions of Y test in the basketball players with ankle instability. The subjects in this study Included 28 basketball players who were selectively divided into two groups based on the ankle instability questionnaire. first group $(\mathrm{n}=16$, mean weight $71.31 \pm 10.49$, mean height $181.75 \pm 9.16 \mathrm{~cm}$, mean age $18.12 \pm$ 1.70 years old) were functionally instable on their ankles, the second group ( $\mathrm{n}=12$, mean weight $73.66 \pm 9.89 \mathrm{~kg}, \mathrm{mean}$ height $183.25 \pm 7.08 \mathrm{~cm}$, mean age $18.41 \pm 1.83$ years old) were healthy basketball players”. Basketball Movement Specific Circuit" protocol was used to achieve basketball-specific fatigue, and Y test was used to quantify postural control. To make sure that fatigue occurred, Borg scale was employed. The result of dependent $\mathrm{T}$ test indicated that dynamic postural control decreased after fatigue in both groups $(\alpha<0.005)$. In addition, the result of the one-way ANOVA demonstrated that there is a statistically significant difference between anterior and posteromedial directions in the group with functional ankle instability and between anterior and posterolateral directions in the healthy group. The results of this study showed that fatigue significantly affected the players with functional ankle instability in posteromedial direction and the healthy players in posterolateral direction.
\end{abstract}

Keywords: Fatigue, Dynamic Postural Control, Functional Ankle Instability, Y Test, Basketball Players

\section{Introduction}

Measurement of postural control is an important tool in the assessment of pediatric, geriatric, and athletic populations for establishing levels of neuromuscular function for the purposes of injury prevention and rehabilitation. Keeping balance in a closed kinematic chain depends on kinematic strategies and orchestrated feedbacks among the leg, knee and ankle. The torsion of ankle joint, the most common sport injury, is prevalent in most sport fields requiring running, jumping, cutting movements, and stepping to the sides such as football, volleyball, and basketball (frigg et al., 2007), (Bruce et al., 2002). Basketball is one of the world's most popular physical activities. Nearly $11 \%$ of the world's population play basketball regularly. Unfortunately, since the number of young male and female basketball players is rising, the rate of injuries also increases (Harmer, 2005). Due to the nature of this sport field, a high percentage of injuries were reported to have occurred in the lower limb and ankle (Harmer, 2005). Damore et al, (2003) stated that the majority of young basketball players' injuries in the lower limb, which were reported to be between $35 / 9$ and 92 percent, were related to the ankle (Damore et al., 2003). The researchers are still trying to reduce the amount of injuries in basketball players; they have mainly focused on risk factors such as proprioception ability, the level of kinematic development, the level of competition, and fatigue (Harmer, 2005). Fatigue is a common phenomenon that occurs during exercises and impairs an athlete's kinematic function (Millet et al., 2004). In the last decade, sports scientists have considered fatigue as a factor which negatively affects sport performance. They also investigated the relation between fatigue and postural 
control and concluded that fatigue and the reduction of postural control can result in skeletal-muscular injury in athletes (Pappas et al., 2007). Several studies have been done on the relation between fatigue and postural control. For instance, Gribble et al, (2004) examined the effect of fatigue and chronic ankle instability on dynamic postural control in posterior, medial, and anterior directions through applying Star Excursion Balance Test. They found that the individuals had less ankle flexion angle and less balance in all the three directions in the ankle with chronic instability (Gribble et al., 2004). Sadeghee et al, (2008), in a study entitled "The effect of functional fatigue on dynamic postural control", employed a functional fatigue protocol (20- minute activity at 7 stations) and a Star Excursion Balance Test in order to induce fatigue and evaluate dynamic balance respectively. They concluded that dynamic postural control was impaired after employing the fatigue protocol (Sadeghee et al., 2008). Sedaghat (2008), in a study entitled "The effect of football-specific fatigue on the dynamic postural control of the football players with functional ankle instability", measured the players' dynamic balance through applying simulator football protocol and analyzing data in the pretest and posttest of Star Excursion Balance Test. The result indicated that, at the end of the protocol, the players with functional ankle instability had significantly impaired postural control (sedaghat , 2008). Hosseinimehr et al, (2010) explored the influence of fatigue on the static and dynamic postural control of the athletes' with ankle injury. The participants of the study consisted of 30 males and females ( 15 subjects in the control group, 15 subjects in the experimental one). In order to measure dynamic balance, measure static balance, and induce fatigue, they used a Star Excursion Balance Test, a test of standing on one foot, and a seven-station functional protocol respectively. The results demonstrated that the healthy athletes' dynamic balance significantly decreased after employing the fatigue protocol (Hosseinimehr et al., 2010).

As it is clear, to investigate the impact of fatigue on the postural control system, most studies used protocols unrelated to exercises and competitions. Furthermore, few studies have been conducted to explore dynamic postural control through functional tests; instead, most of them were carried out to investigate the static postural control system. On the whole, it seems that there is a lack of research into the relationship between dynamic postural control and exercise-induced fatigue and its related concepts. Consequently, it is essential to explore any possible effect of whole body fatigue on dynamic postural control through a functional fatigue protocol which is similar to exercises and competitions and a functional test which measures dynamic postural control.

\section{Methodology}

The subjects of this study were 28 basketball players who participated in the Youth League in Kerman. Their

ages ranged between 16 and 21 years old. The players completed the complacency form, they were handed in Cumberland Ankle Instability Tools (CAIT). In this 30point questionnaire, the score 0 to 27 indicated ankle instability and the score 27 to 30 represented healthy ankle. Then, the participants were selectively divided in two groups: a group of 16 subjects with functional ankle instability and a group of 12 healthy subjects. To make sure that the two groups are exactly similar in terms of the variables of age, weight, height, maximum oxygen consumption, body mass index, and ankle instability score, independent T-Test was held. In other words, T-Test was used to ensure that the only significant difference between the two groups was ankle instability score. The result of the $\mathrm{T}$-Test is presented in the Table 1 .

Table 1. The result of T-Test ran to ensure homogeneity of the two groups

\begin{tabular}{lccc}
\hline \multicolumn{1}{c}{ Statistical index } & T & df & Sig \\
\hline Age & -0.43 & 26 & 0.668 \\
Weight & -0.60 & 26 & 0.553 \\
Height & -0.47 & 26 & 0.642 \\
Maximum oxygen & 0.18 & 26 & 0.851 \\
consumption & -9.76 & 26 & $0.001^{*}$ \\
Ankle instability score & -0.41 & 26 & 0.679 \\
Body mass index & & & \\
\hline
\end{tabular}

The sign * illustrates a significant difference $(\alpha<0.05)$ between the groups on the variable

The $\mathrm{Y}$ balance test device (Intraclass correlation coefficient ranged from 0.89 to 0.93 for the 3 reach directions: anterior 0.89 , posteromedial 0.93 , and posterolateral 0.91 directions) was used to assess the participants' dynamic postural control. In this device, three directions are situated just like Y(Plisky et al., 2006; figur1). To normalize data, this test measured the actual length of the leg which stretched from anterior superior iliac spines to the medial ankle (Gribble et al., 2003). After the experimenter explained the test to the participants, the subjects practiced six times to familiar the procedure. The $\mathrm{Y}$ test was performed on the premier feet. If the right foot was premier, the test was performed in the counterclockwise direction; otherwise in clockwise direction (Gribble et al., 2003).

standing on the left foot

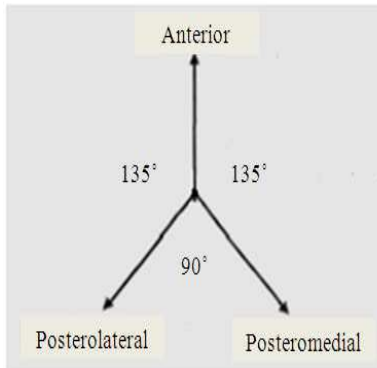

Figure 1. The outline of $Y$ balance test
Standing on the right foot

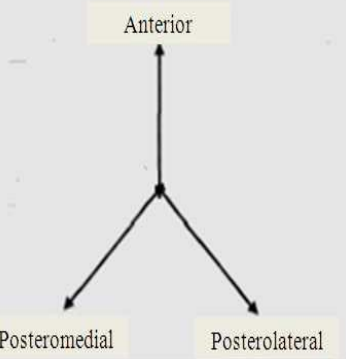


The player stood on one leg in the center of a grid. While maintaining single-leg stance, the player was asked to reach with the free limb in the anterior, posteromedial, and posterolateral directions in relation to the stance foot. The maximal reach distance was measured by marking the tape measure with erasable ink at the point where the most distal part of the foot reached. The trial was discarded and repeated if the player (1) failed to maintain unilateral stance, (2) lifted or moved the stance foot from the grid, (3) touched ground with the reach foot, or (4) failed to return the reach foot to the starting position. The process was repeated while standing on the other leg. The greatest reach distance of the 3 trials for each direction was used for analysis (Figure2) (plisky et al., 2006). Finally, the mean of the three scores was calculated, and the result was divided by the leg length $(\mathrm{cm})$ and multiplied by 100 .

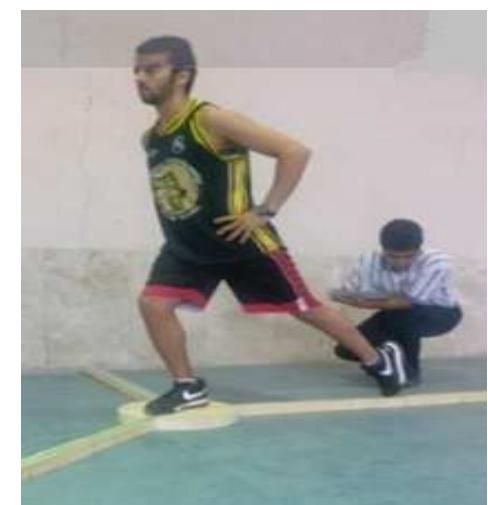

Figure 2. The performance of $Y$ balance test

Basketball-specific fatigue protocol (Basketball Movement Specific Circuit) was employed to induce fatigue (Figure2) (Smith , 2004). This protocol is similar to a basketball game in terms of duration, intensity, and movement patterns. It is applicable in a basketball field. It consists of four 4-minute phases with the heart rate of $90 \%$ to $95 \%$ HRmax. Between each phase, there is a 3 -minute active rest (jogging) with the heart rate of $70 \%$ HRmax.

To ensure that adequate fatigue was attained, the clinicians used the 15-point Borg scale to measure each subjects Rating of Perceived Exertion (RPE). After the participants prepared themselves through a brief warm-up (5-10 minutes of jogging and stretching the lower limb), Y test and PRE were administered as pretests. After they finished the protocol, Y test and PRE were held as posttests (Timothy et al., 2006). In order to compare the postural mean scores in every direction and PRE pretest and posttest in each group, dependent T-Test $(\mathrm{p}<0.05)$ was run. Furthermore, one-way Anova was employed to compare the postural control mean scores in the three directions of $\mathrm{Y}$ test in each group. Then, LSD post hoc test was used to find the exact place of difference.

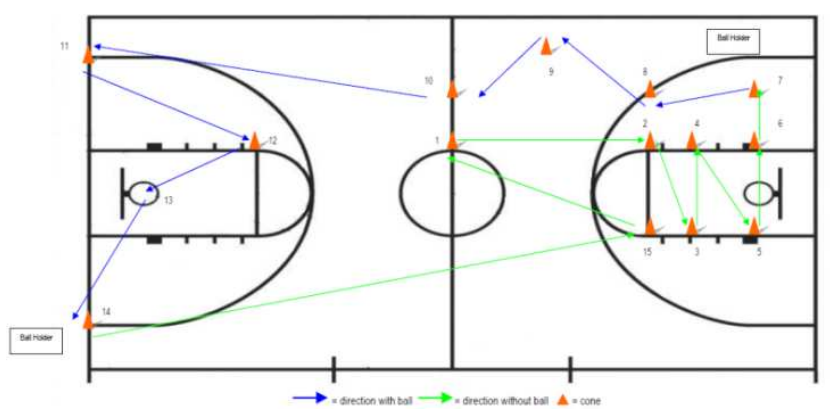

Figure 3. Basketball movement specific training circuit. 1-2 forward sprint; 2 pivot left; 2-3 shuffle left; 3-4 shuffle right; 4-5 shuffle left; 5-6 shuffle right; 6-7 run into vertical jump(collect ball upon landing); 7-10 speed dribble ball around cones; 10-11 speed dribble; 11-12 speed dribble; 12-13 lay-up attempt; 13 lay-up rebound; 13-14 speed dribble(drop ball at 14); 14-15 forward sprint; 15-1 back pedal.

\section{Results}

The result of dependent T-Test between the pretest and posttest on mean scores of reach distance in the three directions are presented in the Table 1. there is a significant difference $(\alpha=0.05)$ in all the three directions. Besides, the results show that the mean scores of postural control in the three directions of the balance test are not equal(tables 2,3). This suggests that there is a significant difference between the mean scores of at least two directions in each group. Tables 4 and 5 list the result of LSD post hoc test. It reveals that there is a statistically significant difference between anterior and posteromedial directions in the group with functional ankle instability and between anterior and posterolateral directions in the healthy group. Moreover, the significant difference $(\mathrm{t}=-14.45, \mathrm{p}=0.000)$ between Borg Scale pretest and posttest, achieved through running T-Test, demonstrated that the intended fatigue really occurred (Graph 1).

Table 2. Comparison between postural control mean scores in each direction in the two groups

\begin{tabular}{|c|c|c|c|c|c|c|c|c|c|c|c|c|}
\hline \multirow[t]{2}{*}{ Directions } & \multicolumn{2}{|c|}{ Mean score } & \multicolumn{2}{|c|}{ Std. deviation } & \multicolumn{2}{|c|}{ Std. error } & \multicolumn{2}{|c|}{ t value } & \multicolumn{2}{|c|}{ df } & \multicolumn{2}{|c|}{$\alpha$} \\
\hline & control & $\begin{array}{l}\text { experim } \\
\text { ental }\end{array}$ & control & $\begin{array}{l}\text { experim } \\
\text { ental }\end{array}$ & control & $\begin{array}{c}\text { experim } \\
\text { ental }\end{array}$ & control & $\begin{array}{l}\text { experim } \\
\text { ental }\end{array}$ & control & $\begin{array}{l}\text { experim } \\
\text { ental }\end{array}$ & control & $\begin{array}{l}\text { experi } \\
\text { mental }\end{array}$ \\
\hline $\begin{array}{l}\text { Anterior } \\
\text { Direction }\end{array}$ & 5.56 & 4.48 & 3.13 & 5.03 & 0.90 & 1.25 & 6.25 & 3.65 & 11 & 15 & 0.000 & 0.003 \\
\hline $\begin{array}{l}\text { Posteromedial } \\
\text { Direction }\end{array}$ & 8.58 & 10.50 & 6.7 & 5.34 & 1.94 & 1.33 & 4.41 & 7.85 & 11 & 15 & 0.001 & 0.000 \\
\hline $\begin{array}{c}\text { Posterolateral } \\
\text { Direction }\end{array}$ & 11.51 & 8.44 & 5.36 & 6.78 & 1.54 & 1.69 & 7.44 & 4.98 & 11 & 15 & 0.000 & 0.000 \\
\hline
\end{tabular}


Table 3. The summery of the result of one-way Anova conducted on the data obtained from the experimental and control groups

\begin{tabular}{ccccccc}
\hline & Group & Sum of squares & Df & Mean squares & F & Sig \\
\hline \multirow{2}{*}{ Between groups } & experimental & 299.574 & 2 & 149.787 & 4.498 & 0.017 \\
& control & 206.501 & 2 & 103.250 & 3.689 & 0.036 \\
\multirow{2}{*}{ Within groups } & experimental & 1498.651 & 45 & 33.303 & & \\
& control & 923.631 & 33 & 27.989 & \\
Total & experimental & 1798.225 & 47 & & \\
& control & 1130.132 & 35 & & \\
\hline
\end{tabular}

Table 4. The result of one-way Anova ran to check the difference between the pairs of mean scores in the group with functional ankle instability

\begin{tabular}{|c|c|c|c|c|c|c|c|}
\hline \multirow{2}{*}{\multicolumn{2}{|c|}{ phase }} & \multirow[t]{2}{*}{ Group } & \multirow{2}{*}{$\begin{array}{l}\text { Mean score } \\
\text { difference }\end{array}$} & \multirow{2}{*}{$\begin{array}{l}\text { Std. deviation of } \\
\text { mean score } \\
\text { difference }\end{array}$} & \multirow[t]{2}{*}{ sig } & \multicolumn{2}{|c|}{$\begin{array}{c}\text { confidence interval }(95 \%) \text { for } \\
\text { mean difference }\end{array}$} \\
\hline & & & & & & minimum & maximum \\
\hline \multirow{2}{*}{1} & \multirow{2}{*}{2} & experimental & $-6.0189^{*}$ & 2.04032 & 0.005 & -10.1284 & -1.9095 \\
\hline & & control & -2.9312 & 2.15982 & 0.184 & -7.3254 & 1.4630 \\
\hline \multirow{2}{*}{1} & \multirow{2}{*}{3} & experimental & -3.9656 & 2.04032 & 0.058 & -8.0751 & 0.1438 \\
\hline & & control & -5.8666 & 2.15982 & 0.010 & -10.2608 & -1.4724 \\
\hline \multirow{2}{*}{2} & \multirow{2}{*}{3} & experimental & 2.0533 & 2.040332 & 0.32 & -2.0561 & 6.1627 \\
\hline & & control & -2.9354 & 2.15982 & 0.183 & -7.3296 & 1.4588 \\
\hline
\end{tabular}

1: anterior direction $\quad$ 2:posteromedial direction $\quad$ posterolateral direction

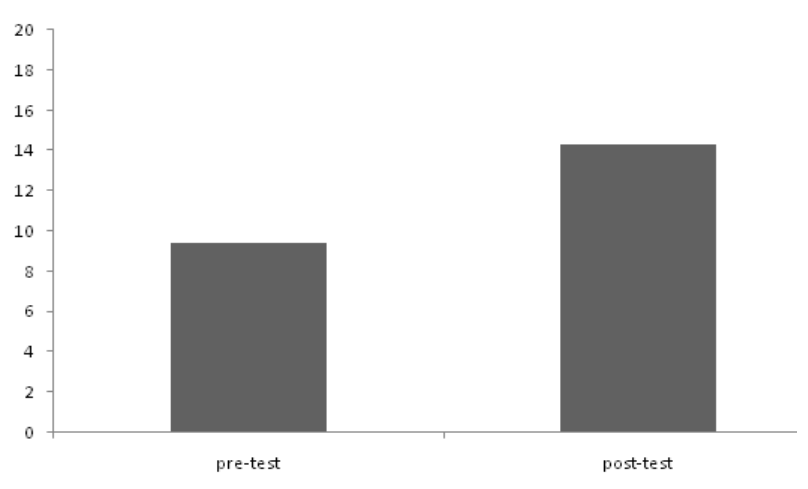

Graph 1. The result of PRE measurement

\section{Discussion and Conclusion}

The main aim of the present study was the comparison of the effect of the amount of fatigue on the three directions of $\mathrm{Y}$ test in the basketball players with ankle instability. The results suggested a relationship between reach operation and time (pretest and posttest). Reach distance in all the three directions in the posttest was lower than the one in the pretest. Besides, the results indicated a significant difference between PRE pretest and posttest mean scores. On the whole, the findings confirm the four research hypotheses: reach distance in all the three directions of the $\mathrm{Y}$ balance test in the pretest will be significantly higher than the one in the posttest. The support of the fourth hypothesis, stating that there will be a significant difference between PRE pretest and posttest mean scores, shows that the intended fatigue was induced in the two phases of the fatigue protocol.

The reduction of the reach distance in the three directions of $\mathrm{Y}$ test after the application of the fatigue protocol can be attributed to the different roles of each of the lower limb muscles in performing the balance test. In their study, Olmsted et al, (2003) found that the foot on which a person leans while performing the test needs knee flexion, leg flexion, and ankle dorsiflexion. Thus, the lower limb requires adequate motion range, strength, the activity of deep receptors, and neuromuscular control (Gribble et al., 2003), (Olmsted et al., 2003). While an individual performs the reach operation, hamstring and quadric muscles are contracted in all directions. The quadric muscle has its most activities in the anterior direction. This can be accounted on the fact that, while performing reach operation, the individual has to lean back and his body should be extended so that he can maintain his balance. In this situation, the gravitational force acting on the upper part of the body causes high knee flexion torque which should be controlled by the extension torque (eccentric contractions) generated by quadric muscles (Earl et al., 2001). The external broad muscle has its most activities in the posteromedial direction. This is because of the muscular stability which occurs against the muscular forces active to perform the reach operation in this direction (Earl et al., 2001). While an individual performs the reach operation, the biceps are also active. The biceps have their most activities in posteromedial and posterolateral directions. This can be explained in terms of the effect of the gravitational force acting on the body, which causes knee flexion torque. In order to perform activities in the posterior 
direction, the person should have flexion in his body so that he can open his foot to the back. In this situation, hamstring muscles should be contracted in an eccentric way so that they can resist against the leg flexion torque. Performing an activity in the lateral direction requires severe lateral leg rotation which results in the activity of the upper part of biceps (Earl et al., 2001). Besides, to obtain the highest reach distance while performing the test in posterolateral and posteromedial directions, the participant needs plantar ankle flexion leading to the sever activity of back shank muscles (Earl et al., 2001).

The findings of the present study indicate that the reduction of reach distance in all the three directions of $Y$ test after the induction of fatigue in the different muscles of lower limb depends on the roles that these muscles plays in performing the reach operation. Regarding the preceding discussion, we can attribute the reduction of postural control mean scores in the posttest to reduced muscle strength, impaired joint position sense, delayed neuromuscular responses. The result gained in this study has a consistency with the findings obtained in other similar researches. Mercer et al, (2003), Nyland et al, (1997) and Rahnama et al, (2003) asserted that fatigue reduces muscular strength. In the same vein, Rozzy and Lefart (1999) and Skinner et al, (1986) claimed that joint position sense (proprioception ability) is impaired due to fatigue. Similarly, Gleeson et al, (1998) and Rozzy et al, (1999) believed that, because of fatigue, neuromuscular firing, the reaction of muscles, and neuromuscular responses are postponed.

Considering the directions of SEBT test, many researchers believed that performing an activity is easier in some directions than the others. To put it in more specific words, performing an activity is easiest in posterior, posteromedial, and medial directions but most difficult in anterior, anterolateral, and lateral directions (Gribble , 2003), (Gribble et al., 2003). Post hoc tests demonstrated that, firstly, it is most difficult to perform an activity in the lateral direction; secondly, reach distance is significantly lowest in anterolateral direction (except the lateral direction); and thirdly, reach distance is randomly highest in posterior and posteromedial directions (Gribble , 2003), (Gribble et al., 2003).In the present study, it was concluded that there is a significant decrease in all directions in both groups after the application of the fatigue protocol. Specifically, the post hoc test proved that the healthy participants displayed more significant difference in posterolateral direction and those with functional ankle instability illustrated more significant difference in posteromedial direction.

\section{References}

[1] Frigg A, Frigg R, Hintermann B, Barg A, Valderrabano V. (2007). The biomechanical influence of tibio talar containment on stability of the ankle joint. Knee Surg Sports Traumatol Arthrosc. 15(11):1355-62.
[2] Bruce D. Beynnon, Darlene F. Murphy, Denise M. Alosa (2002). Predictive Factors for Lateral Ankle Sprains. J Athl Train. 37(4): 376-380.

[3] Karen P Cote, Michael E Brunet, II, Bruce M Gansneder, Sandra J Shultz. (2005). Effects of pronated and supinated foot postures on static and dynamic postural stability. J Athl Train. 2005 Jan-Mar; 40(1): 41-46.

[4] Damore DT, Metzl JD, Ramundo M, Pan S, Van Amerongen R. (2003).Patterns in childhood sports injury. Pediatr Emerg Care. 19(2):65-7.

[5] Earl JE, Hertel J. (2001). Lower-extremity muscle activation during the star excursion balance tests. Journal of Sport Rehabilitation. Vol. 10 Issue 2, p93

[6] Gleeson NP, Reilly T, Mercer TH, Rakowski S, Rees D. (1998). Influence of acute endurance activity on leg neuromuscular and musculoskeletal performance. Medicine and Science in Sports and Exercise 30 (4), 596-608.

[7] Gribble PA. (2003). The star excursion balance test as a measurement tool. Athl Ther Today;8(2):46- 47.

[8] Gribble PA, Hertel J. (2003). Considerations for the normalizing measures of the star excursion balance test. Measurements Phys Educ Exer Sci; 7:89-100.

[9] Gribble PA, Hertel J, Denegar C.R, Buckley EW. (2004). The effects of fatigue and chronic Ankle instability on Dynamic postural control. J of Athletic training. 39 (4): 321329.

[10] Harmer PA. (2005). "Basketball injuries", Med Sport Sci. Basel. vol 49, pp 31-61.

[11] Hosseinimehr H, Daneshmandi H, Norasteh A. (2010). The Effects of Fatigue and Chronic Ankle Instability on Dynamic Postural Control. Physics International 1 (1): 2226.

[12] Mercer T.H, Gleeson N.P, Wren K (2003). Influence of prolonged intermittent high-intensity exercise on knee flexor strength in male and female soccer players. European Journal of Applied Physiology 89 (5),506-508.

[13] Millet GY, R Lepers. (2004). Alterations of neuromuscular function after prolonged running, cycling and skiing exercises. Sports Med., 34: 105- 116.

[14] Nyland JA, Shapiro R, Caborn DN, Nitz AJ, Malone TR (1997). The effect of quadriceps femoris, hamstring, and placebo eccentric fatigue on knee and ankle dynamics during crossover cutting. Journal of Orthopaedic \& Sports Physical Therapy 25 (3), 171-184.

[15] Olmsted LC, Carcia CR, Hertel J, Shultz SJ. (2003). Efficacy of the star excursion balance tests in detecting reach deficits in subjects with chronic ankle instability. J Athl Train. 37, 501-506.

[16] Pappas E, Sheikhzadeh A, Hagins M, Nordin M (2007). The effect of gender and fatigue on the biomechanics of bilateral landings from a jump: Peak values. J Sports Sci and Med. $6: 77-84$

[17] Plisky PJ, Rauh MJ, Kaminski TW, Underwood FB. (2006). Star excursion balance test as a predictor of lower extremity injury in high school basketball players. J Orthop Sports Phys Ther 36: 911-919. 
[18] Rahnama N \& et al (2003). cc. Journal of sport science, $21: 11,933-942$.

[19] Rozzi SL, Lephart SM, Fu FH. (1999). Effects of muscular fatigue on knee joint laxity and neuromuscular characteristics of male and female athletes. Journal of Athletic Training 34 (2), 106- 114.

[20] Sadeghee H, Sershin A, Abbasi A (2008). The effect of functional fatigue on dynamic postural control. Research into Sport Science, 20, 79-94.

[21] Sedaghat M (2008). The effect of football-specific fatigue on the dynamic postural control of the football players with functional ankle instability. Unpublished M.A thesis. Shahid Bahonar University of Kerman.
[22] Smith M. (2004). Basketball skill test for the big men. FIBA Assist Magazine, 07, 59-60.

[23] Skinner H.B, Wyatt M.P, Hodgdon J.A, Conard D.W, Barrack R.L (1986). Effect of fatigue on joint position sense of the knee. Journal of Orthopaedic Research 4 (1), 112-118.

[24] Seliga R, Bhattacharya A, Succop P, Wixhstrom R, Smith D, Willeke K. (1991). Effect of work load and respirator wear on postural stability, heart rate, and perceived exertion. Am Ind Hyg Assoc J;52:417-422.

[25] Timothy A, Kulpa BS. (2006). The Effects of Activity related fatigue on Dynamic postural control as measured by SEBT. Unpublished M.A thesis. Morgantown, West Virginia. 